\title{
Elucidating iron doping induced n- to p- characteristics of Strontium titanate based ethanol sensors
}

\author{
Neha Sarin ${ }^{\text {a, b }}$, Monu Mishra ${ }^{c}$, Govind Gupta ${ }^{\text {, }}$, Ivan P. Parkin ${ }^{\text {d, }}$ Vandna Luthra ${ }^{\text {a, * }}$ \\ a Department of Physics, Gargi College, Siri Fort Road, New Delhi, 110049, India \\ bepartment of Physics \& Astrophysics, University of Delhi, New Delhi, 110007, India \\ ${ }^{\mathrm{c}}$ Physics of Energy Harvesting Division, CSIR-National Physical Laboratory, Dr. K.S. KrishnanRoad, New Delhi, 110012, India \\ d Department of Chemistry, University College London, 20 Gordon Street, London, WC1H OAJ, UK
}

\section{A R T I C L E I N F O}

\section{Article history:}

Received 16 June 2017

Received in revised form

23 October 2017

Accepted 13 November 2017

Available online 14 November 2017

\section{Keywords:}

Strontium titanate

Doping

Ethanol sensing

$\mathrm{n}$ - and p-type gas sensors

XPS

\begin{abstract}
A B S T R A C T
A series of pure and iron doped strontium titanate, $\left(\mathrm{SrFe}_{\mathrm{x}} \mathrm{Ti}_{1-\mathrm{x}} \mathrm{O}_{3} ; \mathrm{x}=0,0.1\right.$ and 0.2$)$ powders were synthesized, characterized and used to fabricate ethanol sensors for low concentration. X-Ray Diffraction (XRD) technique was used to confirm the single phase formation. Microstructural properties of the powders were investigated using scanning electron microscopy (SEM). Electrical conductivity of all the samples at room temperature (RT) was measured. Sensors were optimized for best responsiveness by varying the operating temperature from $350{ }^{\circ} \mathrm{C}$ to $500{ }^{\circ} \mathrm{C}$. The sensor with doping $\mathrm{x}=0.2$ exhibited best sensing response at $400^{\circ} \mathrm{C}$ for ethanol gas. The undoped sensor demonstrated a decrease in resistance on exposure to ethanol gas whereas Fe-doped sensors showed increase in resistance. The doping induced changeover from $\mathrm{n}$ to $\mathrm{p}$ behavior in the sensing response on doping has been investigated and corroborated with an observed shift in the Fermi level position by X-ray photoelectron spectroscopy (XPS). The disparity in gas sensing response clearly demonstrates inter-connection of multiple influencing factors such as electrical conductivity, morphology, porosity and change in chemical composition on doping. The sensors were exposed to ethanol, nitrogen dioxide, carbon monoxide, butane gases at concentration between $5 \mathrm{ppm}$ and $50 \mathrm{ppm}$. The sensor exhibited much reduced relative response to all gases other than ethanol which can be utilized for wide range of applications.
\end{abstract}

(c) 2017 Elsevier B.V. All rights reserved.

\section{Introduction}

The gas sensing abilities of semi-conducting oxides were discovered many years ago [1]. It has matured into an important technology due to multifarious applications in the fields of environment, pollution control, automobiles, domestic safety, personal security, health care etc. In recent times there is an increasing need for the detection of toxic, polluting and smelling gases at low concentrations. For such low level detection of gases, sensors should be sufficiently upgraded in sensitivity and selectivity. Since their discovery, a range of n-type materials have been explored due to high sensitivity towards a variety of gases. However, these materials offer some disadvantages, such as lack of thermal stability, low selectivity, high cross-sensitivity, and large humidity interference. Semi-conducting perovskites $\left(\mathrm{ABO}_{3}\right)$ such as strontium

\footnotetext{
* Corresponding author.

E-mail address: vandna_arora@yahoo.com (V. Luthra).
}

titanate present excellent alternative [2] due to admirable gas sensitivity, mixed ionic-electronic conductivity, tolerance towards higher doping levels and stability over a wide temperature range $[3,4]$. Such structures have two cations with different sizes, which render it amenable to a huge variety of dopant additions. This doping flexibility allows controlling of various properties such as sensitivity and selectivity to optimize sensor performance for particular applications.

$\mathrm{SrTiO}_{3}$ (ST) is an n-type perovskite oxide having promising applications in the field of solar cells, fuel cells, sensors [5,6] etc. It is well established as a gas sensing material; that is inexpensive and stable in chemical and high temperature atmospheres [2,7]. Most of the gas sensing work focuses on hydrocarbon and oxygen sensing of strontium titanate with iron doping at high concentrations of test gas $[5,8,9]$. It was originally used for oxygen sensing in high temperature range $\left(700{ }^{\circ} \mathrm{C}-900^{\circ} \mathrm{C}\right)$ [10]. In its pure state it has rather very low conductivity and is a wide-bandgap semiconductor with $\mathrm{Eg}=3.2 \mathrm{eV}[11,12]$. Nevertheless, its electronic and ionic conductivity can be improved by increasing oxygen vacancy 
concentration by acceptor doping at the Ti site. For instance upon substitution of $\mathrm{B}$-site transition metal in $\mathrm{ABO}_{3}$ structure by an ion stable in oxidation state lower than $4+$, the charge compensation is achieved by oxidation of $B$ ions or by decrease in the oxygen content of perovskites with eventual appearance of oxygen vacancies. Acceptor doping of trivalent elements on the Ti site could be used for inducing p-type conduction $[3,13]$.

Ethanol is a major component of various industrial processes so its detection at low concentrations is crucial for industry related applications, environmental monitoring, breath analysis and also for food stuff quality control. Although p-type materials demonstrate several advantages over n-type materials such as they display reduced cross sensitivity, promote selective oxidation of volatile organic compounds, they show lower humidity interference etc [14]. Ethanol sensing of p-type materials has not been explored extensively. A lot of work has been focused on ethanol sensing of ntype materials such as $\mathrm{TiO}_{2}, \mathrm{ZnO}$ amongst others [15-17]. However, titanium doped chromium oxide (CTO) is a well exploited p-type material for gas sensors $[18,19]$ in contrast to iron doped strontium titanate. Recently, H. Trabelsi et al. [20] reported an initial increase in the resistance of $\mathrm{SrTiO}_{3}$ followed by a decrease with ethanol gas by varying the oxygen vacancy concentration. In another report, $\mathrm{S}$. K. Hodak et al. [21] have reported ethanol sensing of $\mathrm{SrTiO}_{3}$ thin films with gas concentration in range of $100 \mathrm{ppm}-1000 \mathrm{ppm}$. The oxygen sensing property of $\mathrm{SrFe}_{\mathrm{x}} \mathrm{Ti}_{1-\mathrm{x}} \mathrm{O}_{3}$ has been proposed via sonochemical method [22]. However, in present investigation, the ethanol sensing of $\mathrm{Fe}$ doped $\mathrm{SrTiO}_{3}$ has been studied for low concentrations $(5-50 \mathrm{ppm})$. The results of n-type type behavior observed for undoped $\mathrm{SrTiO}_{3}$ and p-type for Fe doped $\mathrm{SrTiO}_{3}$ have been experimentally validated by XPS measurements. Moreover, selectivity to ethanol gas is an important parameter for assessment of sensors performance that has not been addressed in existing reports. To our knowledge, this is the first extensive study of of $\mathrm{p}$ type thick films based on iron doped strontium titanate being used for ethanol sensing at low concentrations. Semiconducting oxides are usually classified according to the direction of change of resistance on exposure to test gases i.e. in n-type (e.g., $\mathrm{In}_{2} \mathrm{O}_{3}, \mathrm{ZnO}, \mathrm{SnO}_{2}$ ) resistance decreases or p-type (e.g., $\mathrm{Cr}_{2} \mathrm{O}_{3}, \mathrm{CuO}$ ) resistance increases (for reducing gas) [23]. Here, we provide experimental evidence for doping induced change in behavior from n-to p-type. The purpose of the present study is to develop novel p-type gas sensors with enhanced gas sensitivity and selectivity. The pure and iron doped strontium titanate was prepared by a solid state route. The structure and electrical properties of the samples have been reported. The sensors have been tested for various gases. The effect of doping on the Fermi level position has been studied using X-ray photoelectron spectroscopy (XPS) which substantiates the n- and p-type gas sensing behavior observed for pure and Fe-doped sensors respectively.

\section{Experimental}

\subsection{Material preparation}

All samples were prepared using solid state reaction method. Powders of $\mathrm{SrCO}_{3}$ (Aldrich), $\mathrm{TiO}_{2}$ (Merck), $\mathrm{Fe}\left(\mathrm{NO}_{3}\right)_{2} \cdot 9 \mathrm{H}_{2} \mathrm{O}$ (Merck) were used as precursors. Three compositions were prepared: $\mathrm{SrTiO}_{3}$ (ST0), $\mathrm{SrFe}_{0.1} \mathrm{Ti}_{0.9} \mathrm{O}_{3}$ (ST1) and $\mathrm{SrFe}_{0.2} \mathrm{Ti}_{0.8} \mathrm{O}_{3}$ (ST2). Appropriate amounts of powders mixed with isopropyl alcohol (IPA) were milled using planetary ball mill for $24 \mathrm{~h}$ using Zirconia balls. The samples were dried and ground further by mixing with IPA in a mortar and pestle for $2 \mathrm{~h}$. The powders were then calcined at $800^{\circ}$ $\mathrm{C}, 1000^{\circ} \mathrm{C}$ and $1100^{\circ} \mathrm{C}$ for $3 \mathrm{~h}$ in closed alumina crucibles in each case. The optimum conditions for calcination were observed at $1100^{\circ}$ C. The resulting powders were used for various characterizations and gas sensing measurements. The electrical characterizations were carried out on pelleted samples which were obtained by mixing and grinding the powders with polyvinyl alcohol (PVA) as a binder for an hour. A co-axial hydraulic press was used to obtain pellets of diameter $10 \mathrm{~mm}$ and thickness $\sim 1.5 \mathrm{~mm}$.

\subsection{Preparation of sensors}

Sensors of pure and iron doped strontium titanate were fabricated onto $3 \times 3 \mathrm{~mm}^{2}$ alumina substrates containing laser etched interdigitated gold electrodes for resistance measurements on the upper layer with electrode gap $\sim 0.15 \mathrm{~mm}$, (see Fig. 1). A platinum heater track housed at the bottom of the tile was used to achieve the desired temperature (Courtesy: City Technology).

Inks for screen printing were prepared by mixing the respective powders with a viscous organic vehicle (ESL-400, Agmet Ltd.) [23] by grinding in a mortar and pestle until a smooth homogeneous suspension was obtained. Inks were then screen printed using DEK1202 screen printer that pushed the ink through a suitably masked porous layer onto the strip of alumina substrates. After each print, the layer was dried under an infra-red lamp for 20 min. A total of 5 layers were deposited. Subsequently, all the individual sensors were fired at $600^{\circ} \mathrm{C}$ for an hour in an Elite Thermal Systems BRF15 furnace to evaporate the organic vehicle which yielded a solid material on the designated area. The sensors were bound onto the brass pins in standard polysulphide housing wire $0.0508 \mathrm{~mm}$ thickness, Alfa Aesar) and a Mac Gregor DC601 parallel gap resistance.

\subsection{Characterization techniques}

The samples were characterized using X-ray diffraction (XRD), Scanning Electron Microscope (SEM) and X-ray Photoelectron Spectroscopy (XPS). The phase purity of the powders was investigated using X-ray diffractometer (Bruker, D8 advanced diffractometer, Germany) using a $\mathrm{CuK}_{\alpha}(\lambda=1.541 \AA)$ radiation where the patterns were collected over a range of $10^{\circ}-80^{\circ}$ with a scan rate of $2^{\circ} / \mathrm{min}$. SEM micrographs of fracture parts of calcined pellets were collected using JEOL JSM 6610 microscope, in secondary electron mode using $20 \mathrm{kV}$ probe voltage. The XPS measurements were performed in Ultra-high Vacuum (UHV) based OMICRON Multiprobe Surface Analysis system operating at base pressure of $5 \times 10^{-11}$ Torr. Spectra were recorded using Monochromatized $\mathrm{AlK}_{\alpha}$ $(1486.7 \mathrm{eV})$ radiation source. The valence band (VB) was probed in order to identify the nature of the material in pure and doped forms. The position of the VB maximum was determined by extrapolating a linear fit to leading edge [24]. Electrical studies of the prepared samples were measured using Keithley 2400 source meter at room temperature. The pellets used were coated with silver paste on both sides to form a metal-semiconductor-metal structure and fired at $300{ }^{\circ} \mathrm{C}$ in a muffle furnace. The room temperature conductivity was measured by I-V characteristics.

\subsection{Gas sensing procedure}

Gas sensing tests were conducted in an in-house rig, consisting of 12 ports, connected to standard gas supplies and controlled by four mass flow controllers [25]. Usual tests were done to stabilize the sensors. Sensors were kept in air for 1800s to establish the baseline resistance. This was followed by six pulses of increased concentration of target gas introduced for 600 s followed by 1200 s of air pulses for the sensor to retrieve the initial baseline. Sensors were tested for various gases at concentration of 5-50 ppm. Wheatstone bridge circuits allowed the integrated heater tracks on the base of the alumina tiles to set the operating temperatures of 

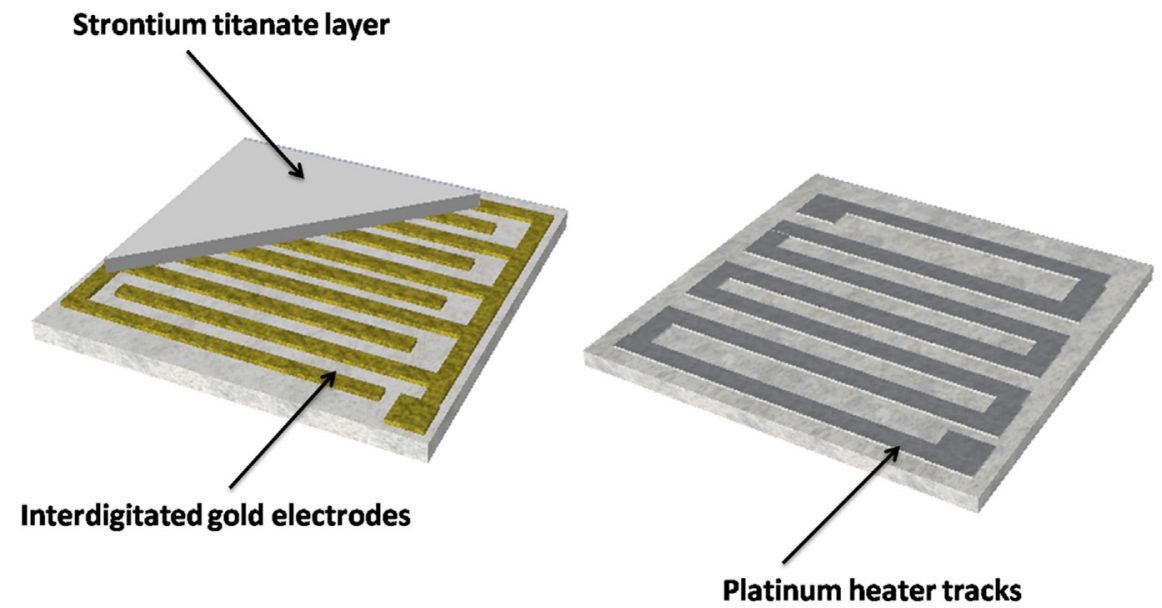

Fig. 1. Schematic diagram of sensor film on alumina substrate with interdigitated gold electrodes and platinum heater track.

the sensors. The temperatures were varied between $350{ }^{\circ} \mathrm{C}$ $-500{ }^{\circ} \mathrm{C}$ in order to optimize the gas sensing response at different concentration of gas pulses. Each test was then repeated twice to ensure the consistency and reliability of the recorded measurements.

\section{Results and discussions}

\subsection{X-ray diffraction}

XRD pattern is indicative of the crystalline nature of the samples. Fig. 2 shows XRD patterns of ST0, ST1, and ST2. The effect of Fe doping on strontium titanate was studied. It was observed that all samples were perovskite phase with cubic structure. It was in agreement with the reported structure of $\mathrm{SrTiO}_{3}[26,27]$ and can be indexed to JCPDS card 86-0177. No additional peaks were observed in composition $\mathrm{x}=0.0,0.1$ samples indicating that $\mathrm{Fe}$ is dissolved within the crystal lattice and shows no secondary phase [28]. However, very minute low intensity peak starts appearing for the composition $\mathrm{X}=0.2$. Although no splitting of the (110) reflection was observed. Also no double peaks are observed in the range $45^{\circ}-48^{\circ}$ which is characteristic of $\mathrm{SrTiO}_{3}$ cubic lattice [28]. The ionic radius of $\mathrm{Fe}^{3+}(0.585 \AA)$ is smaller than $\mathrm{Ti}^{4+}(0.605 \AA)$, hence doping of $\mathrm{Fe}$ lead to a decrease in the lattice parameter and interplaner spacing in iron doped strontium titanate [26]. This decrease is also an

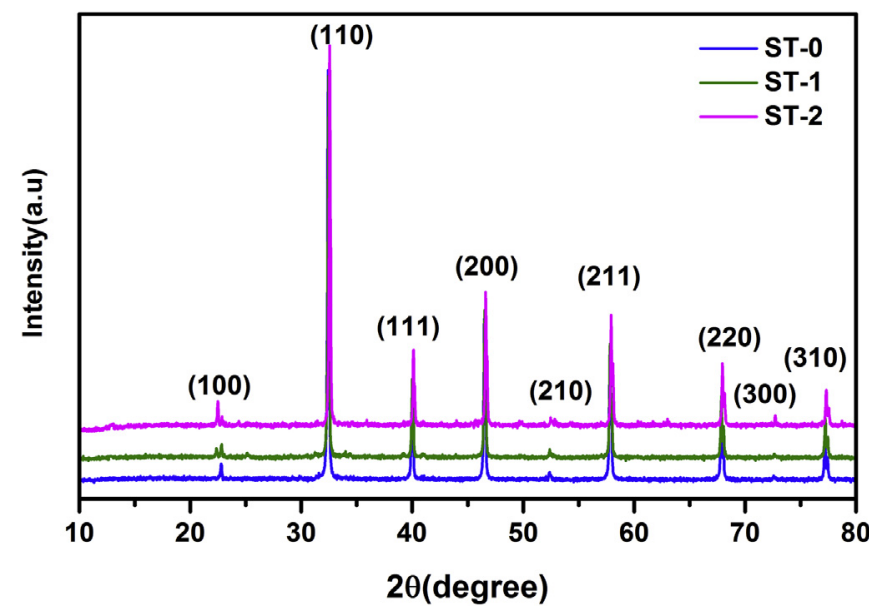

Fig. 2. XRD pattern of ST0, ST1, ST2 (from bottom to top) prepared by solid state route. indication of formation of disorder or some changes in the local structure which may be the reason for variation in properties of Fedoped samples as compared to pure samples.

\subsection{Scanning electron microscope}

The cross-sectional scanning electron microscope (SEM) images of the fractured pellets were recorded at various magnifications. Fig. 3 shows SEM images at 17000x magnification indicating porous nature of the material. Fig. 3a also shows the cubic structure of pure $\mathrm{SrTiO}_{3}(\mathrm{STO})$. The average grain size for ST0 was obtained to be around $\sim 240 \mathrm{~nm}$ which increases with increasing Fe content to $\sim 350 \mathrm{~nm}$ for ST1 and $\sim 500 \mathrm{~nm}$ for ST2, measured using ImageJ software. This suggests that Fe doping assist in growth of grain size as mean particle size increases due to high oxidization tendency [29].

\subsection{Gas sensing}

The gas sensing response for the reducing gas is defined as the ratio of the sensor resistance in gas $R_{g}$ to the baseline resistance $R_{0}$ [S $=R_{g} / R_{0}$ for p-type and $S=R_{0} / R_{g}$ for $n$-type] where baseline resistance is calculated as the average resistance prior to the first gas pulse [23]. All the sensors were operated at three different temperatures i.e., $350{ }^{\circ} \mathrm{C}, 400{ }^{\circ} \mathrm{C}$ and $500{ }^{\circ} \mathrm{C}$ for ethanol gas. Fig. 4 show an increase in resistance of samples operated at $400^{\circ} \mathrm{C}$ as the concentration of test gas increases. It was observed that doped samples ST1, ST2 exhibit p-type behavior whereas from the Fig. 4 (inset) it can be seen that ST0 shows n-type behavior. These results clearly illustrate changeover from n-to p-behavior via Fedoping. Fig. 5a and $\mathrm{b}$ demonstrates gas sensing response of pure and $\mathrm{Fe}$-doped $\mathrm{SrTiO}_{3}$ to ethanol vapor at $400{ }^{\circ} \mathrm{C}$ and $500{ }^{\circ} \mathrm{C}$ from 5 to $50 \mathrm{ppm}$ concentration. The sensors exhibited conductive responses to ethanol vapor at different temperatures. ST2 showed a maximum sensing response of 16.91 at $400{ }^{\circ} \mathrm{C}$ as compared with ST0 or ST1. The response to ethanol gas at temperature $400^{\circ} \mathrm{C}$ is seen to be higher than the response observed at $500{ }^{\circ} \mathrm{C}$, however, the resistance of the sensors was very high at $350^{\circ} \mathrm{C}$ (Table 1). Fig. 6 shows the response as a function of concentration at operating temperature of $400{ }^{\circ} \mathrm{C}$. It is observed that gas response is found to increase with increase in concentration which may be due to larger availability of target gas in the atmosphere surrounding the sensor. Similar gas sensing tests were performed for variety of gases such as $\mathrm{C}_{4} \mathrm{H}_{10}, \mathrm{CO}, \mathrm{NO}_{2}$ (see Fig. 7) and gas sensing responses were recorded. The sensors demonstrated least cross sensitivity to other 


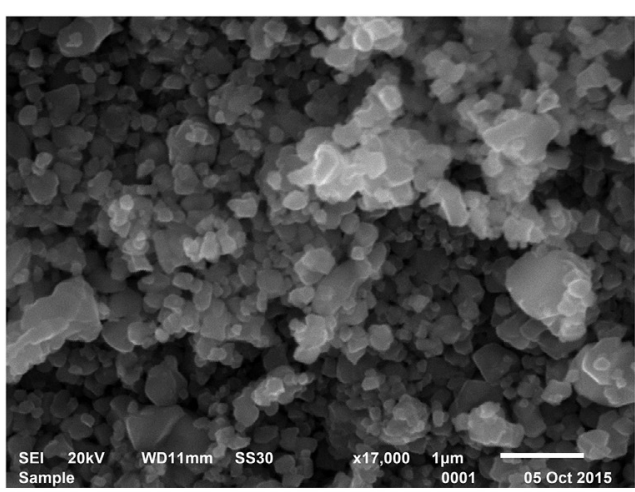

a)

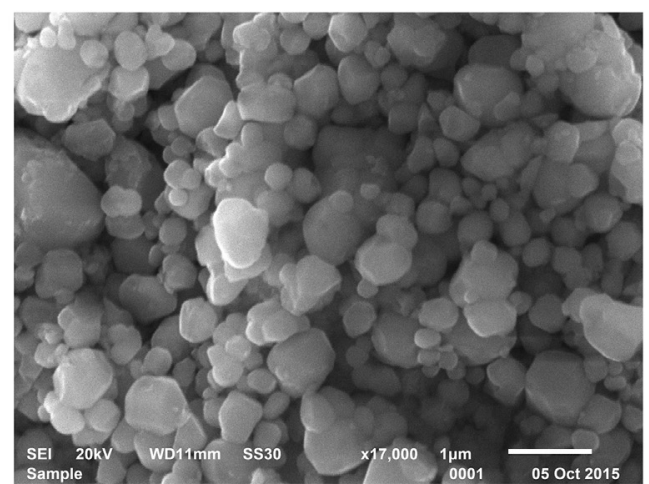

b)

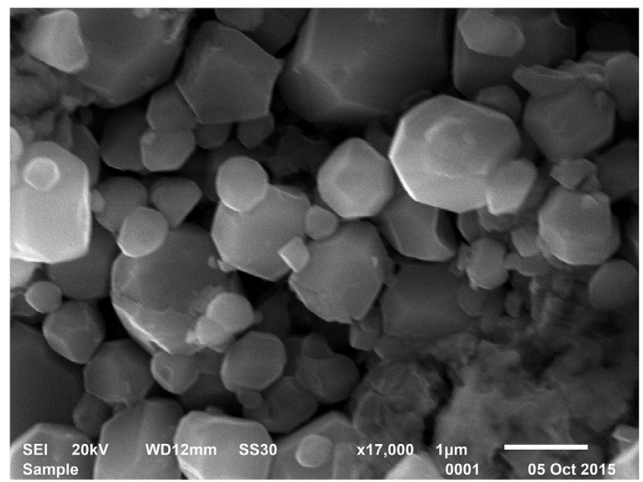

c)

Fig. 3. Scanning electron microscope graphs for a) ST0, b) ST1, c) ST2 samples at a magnification of 17000x.

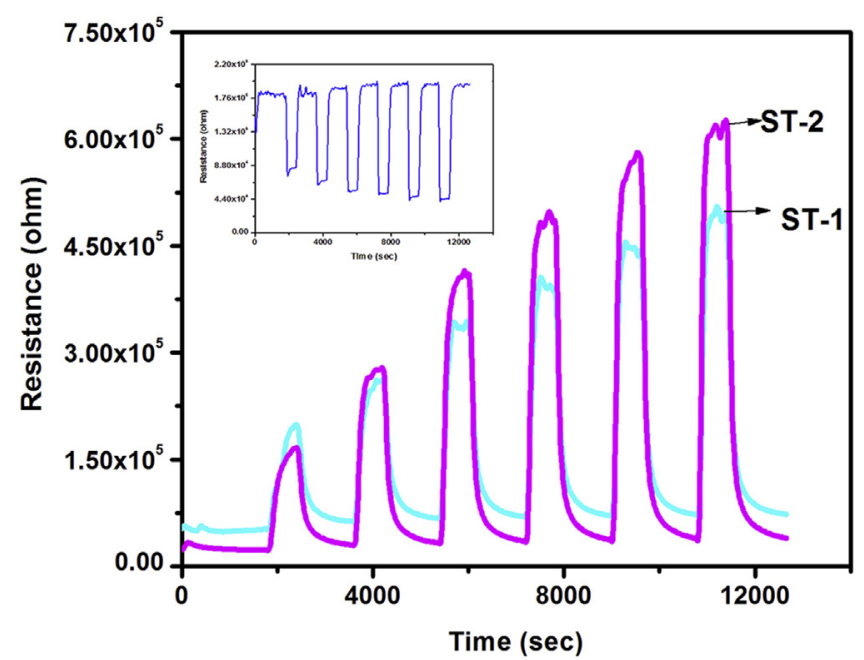

Fig. 4. Change in resistance of sensors on exposure to ethanol gas. (Inset) ST0 shows ntype characteristics, ST1 and ST2 show p-type characteristics.

gases, however displayed an enhanced sensitivity and selectivity towards ethanol gas. The gas sensing tests were performed for many cycles and the response was monitored after a gap of 2 months since their first exposure to ethanol gas. It can be observed form Fig. 8 that no appreciable change was observed in the gas sensing response, the results show good stability and repeatability.

Iron doped $\mathrm{SrTiO}_{3}$ displayed higher response than pure $\mathrm{SrTiO}_{3}$ at $400{ }^{\circ} \mathrm{C}$ as shown in Fig. 5. It could be attributed to change in microstructure, change in chemical composition on doping and higher porosity as compared to a pure sample [17]. The increase in conductivity is observed on substitution of $\mathrm{Ti}^{4+}$ ions by $\mathrm{Fe}^{3+}$ ions which exhibit an expected p-type sensing behavior in the presence of reducing gas $[30,31]$ i.e., when ethanol gas is added in the atmosphere around the sensor, the resistance increases. This is according to the understanding of p-type materials whereas n-type materials observe inverse effect.

The effect of ethanol gas on different perovskite materials as surveyed from the literature is summarized in Table 2. It can be observed that there are reports of perovskite materials tested for ethanol gas at higher concentrations (300 ppm -1000 ppm). Whereas there is scarcely any report on ethanol sensing of Fedoped $\mathrm{SrTiO}_{3}$ notably at low concentration (50 ppm).

\subsection{DC conductivity}

Pellets of pure and doped $\mathrm{SrTiO}_{3}$ samples were calcined at $1100{ }^{\circ} \mathrm{C}$ and dc conductivity of the samples was measured using Keithley 2400 source meter at room temperature. The dc conductivity of the samples was calculated from the linear regions of the I$\mathrm{V}$ curves (see Fig. 9). The dc conductivity was calculated using following equation:

$\sigma_{d c}=\frac{t}{R A}$

where, $\sigma_{\mathrm{dc}}$ is dc conductivity having units $\Omega^{-1} \mathrm{~cm}^{-1} \mathrm{t}$ is the thickness in $\mathrm{cm}, \mathrm{A}$ is the area having units $\mathrm{cm}^{2}$ and $\mathrm{R}$ is the resistance of the samples having units ohm $(\Omega)$.

It is observed from Table 3 that magnitude of dc conductivity in Fe doped samples is higher than pure samples. This variation in the conductivity can be attributed to replacement of $\mathrm{Ti}^{4+}$ ions by $\mathrm{Fe}^{3+}$ 


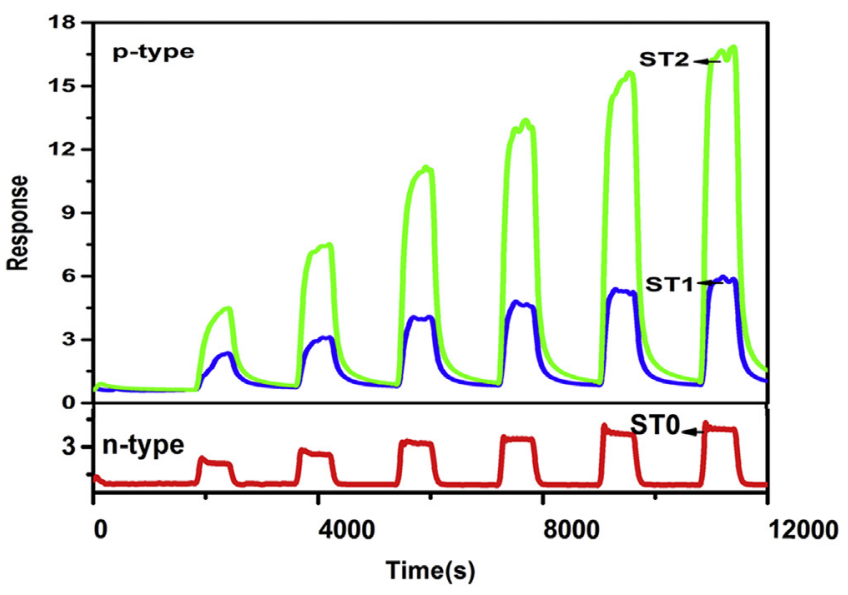

a)

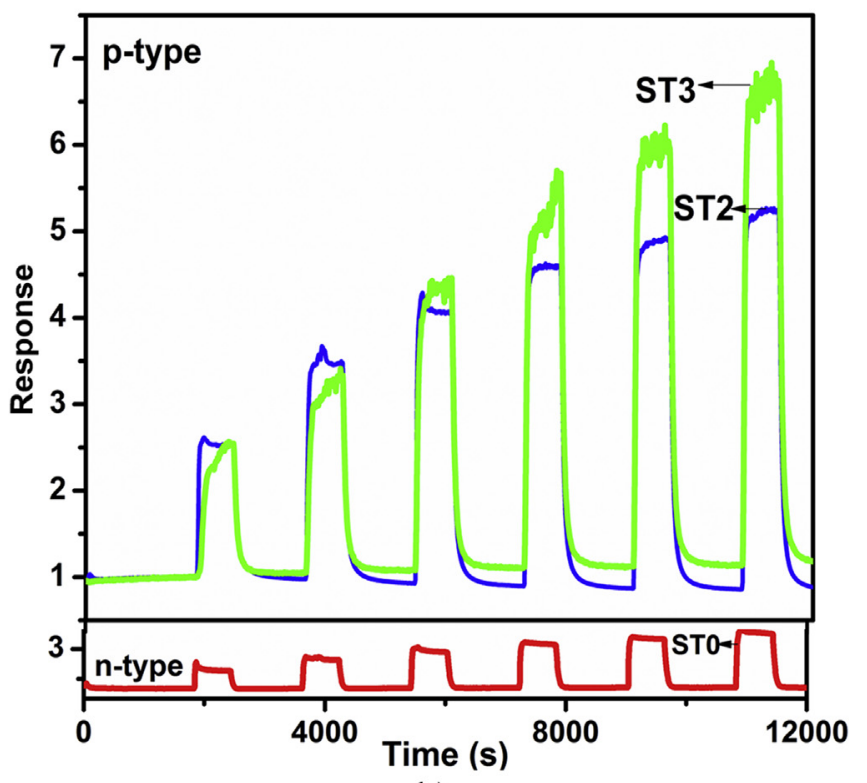

b)

Fig. 5. Relative gas sensing response of pure and doped samples for 5, 10, 20, 30, 40 and $50 \mathrm{ppm}$ ethanol gas at a) $400{ }^{\circ} \mathrm{C}$ and b) $500{ }^{\circ} \mathrm{C}$.

Table 1

Sensor response at various temperatures to ethanol gas at $50 \mathrm{ppm}$.

\begin{tabular}{llllll}
\hline S.No & Sample & $350{ }^{\circ} \mathrm{C}$ & $400{ }^{\circ} \mathrm{C}$ & $500{ }^{\circ} \mathrm{C}$ & \\
\hline 1. & ST0 & Resistance high & 4.48 & 3.70 & n-type $\left(\mathrm{R}_{\mathrm{o}} / \mathrm{R}_{\mathrm{g}}\right)$ \\
2. & ST1 & Resistance high & 6.77 & 4.51 & p-type $\left(\mathrm{R}_{\mathrm{g}} / \mathrm{R}_{\mathrm{o}}\right)$ \\
3. & ST2 & Resistance high & 16.91 & 5.88 & p-type $\left(\mathrm{R}_{\mathrm{g}} / \mathrm{R}_{\mathrm{o}}\right)$ \\
\hline
\end{tabular}

ions. Consequently, resulting in an increased concentration of ptype carriers and therefore an increase in conductivity.

It has been observed that acceptor like dopants such as iron or cobalt increase the p-type conductivity behavior and decreases the n-type conductivity [36]. Also, doping with iron is most effective as variable valences of iron lead to changes in Fermi level position in bandgap and thereby results in an increased the conductivity. The effect of iron doping as a function of partial pressure of oxygen $\left(\mathrm{p}\left(\mathrm{O}_{2}\right)\right)$ on the conductivity changes has been studied by various researchers $[37,38]$ who propose that increasing the iron content can enhance the conductivity of the sample. This implies that band gap (Eg) decreases with increasing iron doping. The conductivity of

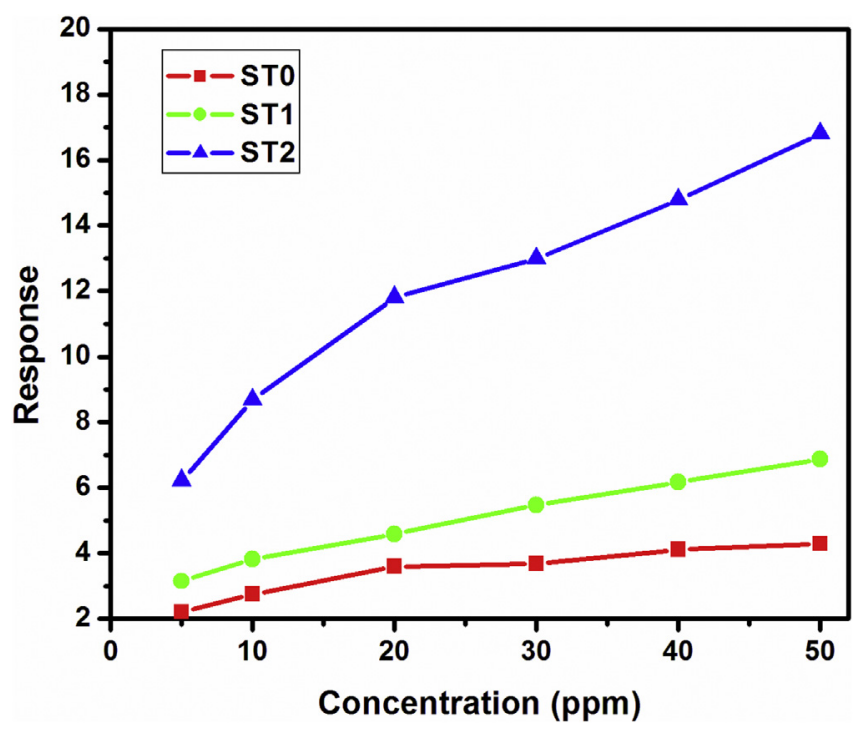

Fig. 6. Response of pure and doped samples at concentrations between 5 and $50 \mathrm{ppm}$ in a 600 s exposure to ethanol gas at $400{ }^{\circ} \mathrm{C}$.

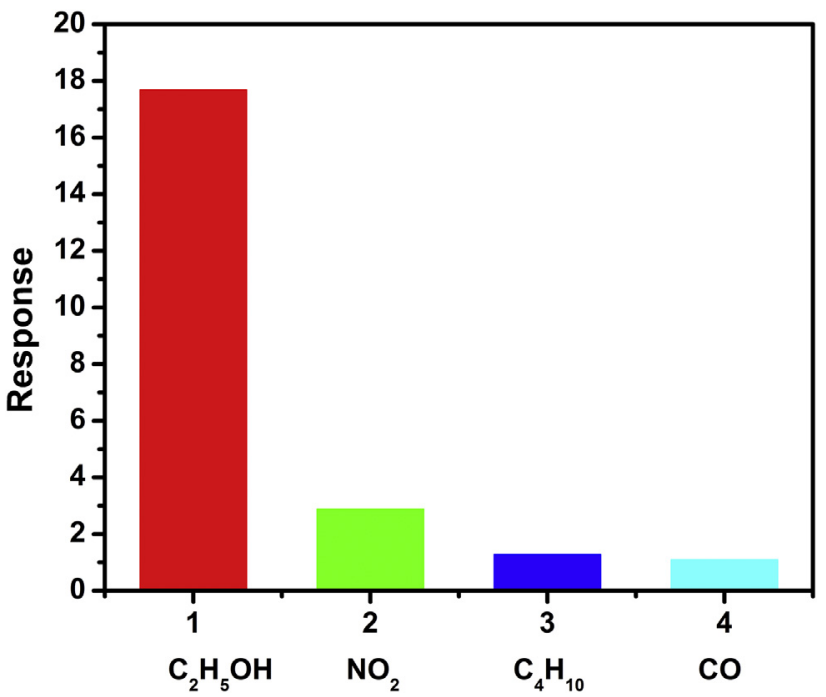

Fig. 7. Response of ST2 to a variety of gases at $50 \mathrm{ppm}$ and an operating temperature of $400{ }^{\circ} \mathrm{C}$.

ST2 sensor is higher than ST0, proving that some $\mathrm{Fe}^{3+}$ ions replaces $\mathrm{Ti}^{4+}$ ions and leads to changes in the conductivity of the sample.

\subsection{X-ray photoelectron spectroscopy}

XPS studies were done in order to record the changes in the position of valence band maxima to unpin the change in $n$ to $p$ behavior due to Fe-doping. Estimates of the Fermi level (FL) position can be obtained by measuring the valence band maxima, which is expected to be half the band gap energy for an intrinsic semiconductor [39]. In n-type material, the FL is located just at the bottom of the conduction band (CB), as in $\mathrm{SrTiO}_{3}$ the band gap is about $3.2 \mathrm{eV}$ [11] and the energy between the top of the VB and the FL is about $3.2 \mathrm{eV}$. However, in p-type material, the FL is located just at the top of VB. If the electronic structure obeys the rigid-band model [40], the position of the FL for p-type materials would be located below the half of the band gap. 


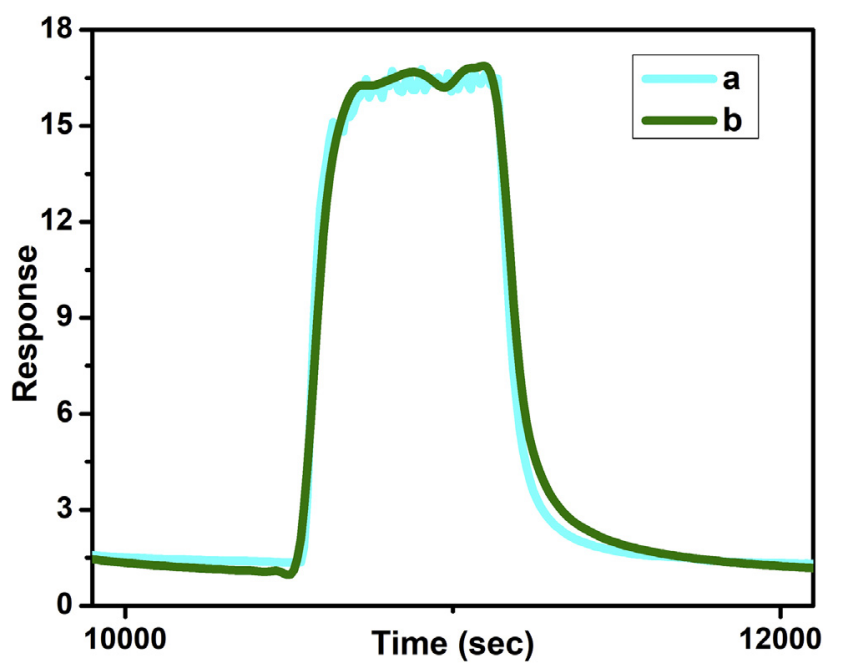

Fig. 8. Gas sensing response of ST2 at $400{ }^{\circ} \mathrm{C}$ at $50 \mathrm{ppm}$ to ethanol gas (curve a). The response taken after a gap of two months is also shown (curve b).

Table 2

Comparison of present data with some existing data on different perovskite materials.

\begin{tabular}{lllll}
\hline S.No. & Sample & ppm & Sensitivity & Reference \\
\hline 1. & $\mathrm{SmFe}_{1-\mathrm{x}} \mathrm{Ni}_{\mathrm{x}} \mathrm{O}_{3}$ & 500 & 57.8 & Ref [30] \\
2. & $\mathrm{LaMg}_{\mathrm{x}} \mathrm{Fe}_{1-\mathrm{x}} \mathrm{O}_{3}$ & 400 & 104 & $\operatorname{Ref}[32]$ \\
3. & $\mathrm{LaFeO}_{3}$ & 1000 & 259 & $\operatorname{Ref}[33]$ \\
4. & $\mathrm{SrFeO}_{3}$ & 1000 & 20 & $\operatorname{Ref}[34]$ \\
5. & $\mathrm{SmFe}_{1-\mathrm{x}} \mathrm{Co}_{\mathrm{x}} \mathrm{O}_{3}$ & 300 & 80.78 & $\operatorname{Ref}[35]$ \\
6. & $\mathrm{SrFe}_{\mathrm{x}} \mathrm{Ti}_{1-\mathrm{x}} \mathrm{O}_{3}$ & 50 & 16.91 & Present work \\
\hline
\end{tabular}

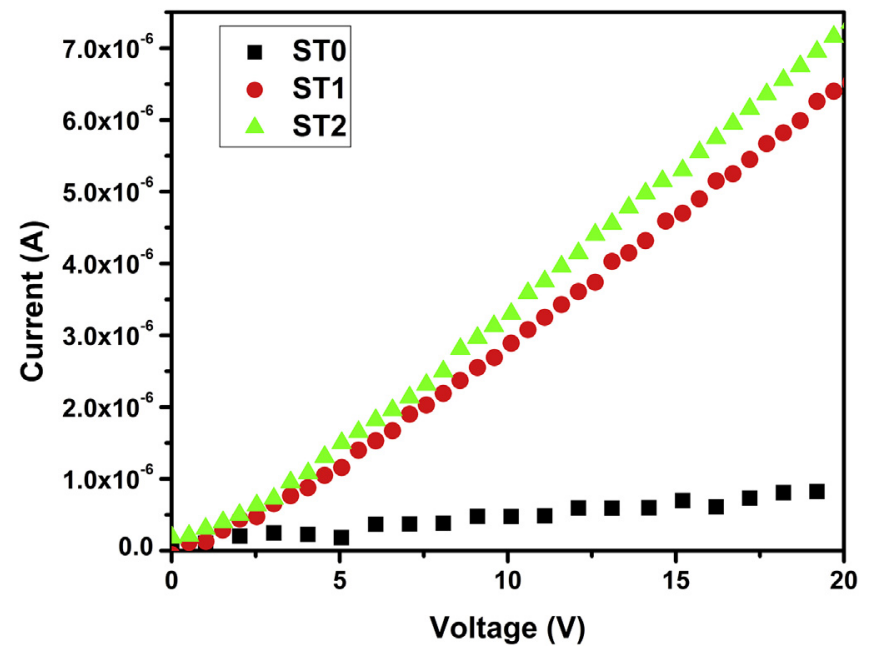

Fig. 9. Room temperature V-I curve for ST0, ST1, ST2.

Table 3

Conductivity values of ST0, ST1, and ST2 at room temperature.

\begin{tabular}{lll}
\hline S.No & Sample & DC Conductivity $\left(\Omega^{-1} \mathrm{~cm}^{-1}\right)$ \\
\hline 1. & ST0 & $4.95 \times 10^{-9}$ \\
2. & ST1 & $8.07 \times 10^{-8}$ \\
3. & ST2 & $1.004 \times 10^{-7}$ \\
\hline
\end{tabular}
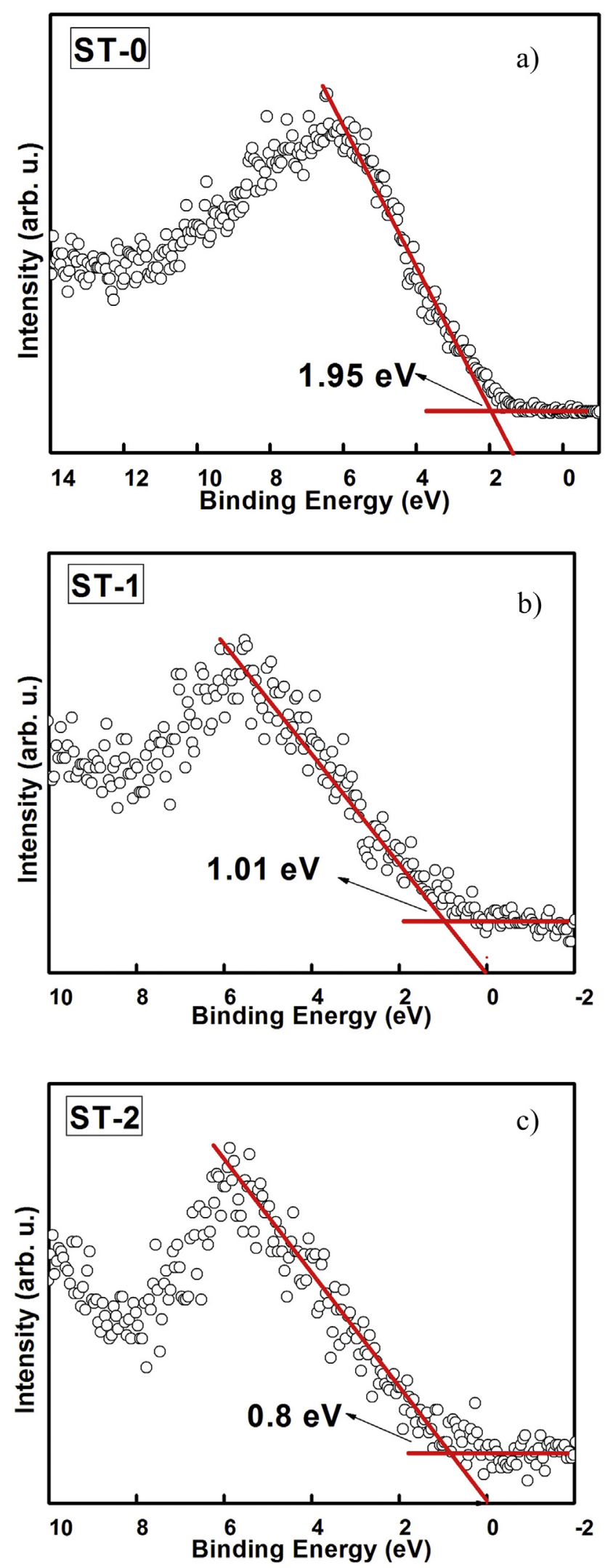

Fig. 10. XPS valence band spectra of a) ST0, b) ST1, c) ST2 acquired using AlK $(1486.7 \mathrm{eV})$ radiation source. 
Fig. 10a shows the valence band maxima as obtained by extrapolating the leading edge of the VB was observed to be $1.95 \mathrm{eV}$ for pure sample. By taking into account the uncertainties and errors on the VB determination $( \pm 0.1 \mathrm{eV})$ is estimated to be $(1.95 \pm 0.2) \mathrm{eV}$ for ST0. From the literature the band gap for $\mathrm{SrTiO}_{3}$ is reported to be $3.2 \mathrm{eV}[11,41]$, which is reasonably close to twice the recorded value for the VB maxima. For $\mathrm{Fe}$ - doped $\mathrm{SrTiO}_{3}$, the $\mathrm{FL}$ position as measured by VB maxima (see Fig. 10b-c) shifts slightly lower to values $(1.01 \pm 0.2) \mathrm{eV}$ and $(0.82 \pm 0.2) \mathrm{eV}$ for ST1 and ST2 respectively. Therefore, it is evident that the FL for Fe-doped samples shifts towards the VB. Furthermore, quantitative analysis demonstrates that FL of Fe-doped samples are located below the half of band gap, thus confirming p-type nature of doped samples. This suggests an increase in the number of holes due to doping of trivalent $\mathrm{Fe}^{3+}$ in place of quadrivalent $\mathrm{Ti}^{4+}$.Thus, indicating an increase in the p-type character of the samples as opposed to n-type character of the intrinsic sample which is in accordance with the recorded gas sensing behavior of the samples.

\subsection{Gas sensing mechanism}

Semi-conducting metal oxides exhibit a change in conductivity due to adsorption or desorption of gas molecules. This change in the conductivity helps us to get information about the gas response signal $[42,43]$. The change in the conductivity is dependent on the electrons having an appropriate amount of energy to jump from the valence to the $C B$ [23]. A space charge region is formed due to transfer of electrons during adsorption and desorption process. The width of this space charge region acts as a potential barrier in the conduction process and stimulates changes in the FL. This process of creation or annihilation of electrons from the CB results in band bending and FL modulation. The change in conductivity is brought about by an upward or downward shift in FL within the band gap of the material. In n-type materials for an oxidizing gas the band bends upwards due to depletion of electrons and band bends downwards due to accumulation of electrons for reducing gases. The inverse is true for p-type materials [44]. Although both $\mathrm{n}$ and $\mathrm{p}-$ type semiconductors establish electrical core shell layer and forms space charge region by adsorbing oxygen, nevertheless they exhibit significantly different conduction mechanisms.

In n-type semiconductor material (ST0), in an oxygen containing environment adsorbed oxygen is always present on the sensor surface $[8,42]$. At elevated temperatures, molecular oxygen adsorbs on the surface by trapping electrons from the $\mathrm{CB}$ of the material forming oxygen anions $\left(\mathrm{O}_{2}^{-}, \mathrm{O}^{-}, \mathrm{O}^{2-}\right)(\mathrm{Eq}$. (2)). This changes the $\mathrm{FL}$ leading to formation of depletion region $[45,46]$. When the sensor is exposed to reducing gas $(\mathrm{R})$, the adsorbed oxygen anions are used to oxidize the reducing gas. As a result, trapped electrons are set free which decreases the resistance of the sensor proportional to the concentration of the reducing gas.

$\mathrm{O}_{2}($ gas $)+2 e^{-}($surface $) \rightarrow O_{\text {ads }}^{2-} /\left(2 O_{\text {ads }}^{-}\right)$

In doped $\mathrm{SrTiO}_{3}(\mathrm{ST} 1, \mathrm{ST} 2)$, trivalent iron ion $\left(\mathrm{Fe}^{3+}\right)$ replacing quadrivalent titanium ion $\left(\mathrm{Ti}^{4+}\right)$ is known as acceptor doping, leading to p-type character. In this case, the adsorbed oxygen molecules are ionized into $\mathrm{O}_{2}^{-}$ions by attracting electron from the VB. This induces a hole accumulation layer, which leads to a lower resistance. As the temperature increases, the oxygen molecules dissociate into oxygen atoms which are adsorbed separately. The electric charge on the surface is thus formed by $\mathrm{O}^{-} / \mathrm{O}^{2-}$ ions (Eq. (2)).

Now, adding reducing gas around the sensor allows the capture of adsorbed oxygen ions and consequent return of trapped electrons to the $\mathrm{VB}$. This process reduces the electric charge of the accumulation zone and the concentration of holes. Thus, leading to an increase in the resistance. It is described in the case of ethanol by the reaction [47]:

$$
\mathrm{C}_{2} \mathrm{H}_{5}-\mathrm{OH}+\mathrm{O}_{\text {ads }}^{-} \rightarrow \mathrm{CH}_{3}-\mathrm{CHO}+\mathrm{H}_{2} \mathrm{O}+e^{-}
$$

However, if the hole accumulation layer is smaller than the particle dimensions, then a slight change in the concentration of holes due to electron-hole recombination will not lead to significant variation, as conduction in p-type semiconductors occurs along the outer shell [47]. These observations are consistent with the previously reported results [31,44].

The thermodynamic equilibrium between adsorption and desorption generally shifts towards desorption at elevated temperature. The more it becomes prominent, the less oxygen is adsorbed on the surface. Thus few holes are destroyed by the electrons present in the $\mathrm{CB}$. Hence, the resistance is reduced [31]. But above an optimum temperature, the redox reaction taking place on the surface proceeds very rapidly and the concentration of the analyte becomes diffusion limited and the concentration detected by the sensor tends towards zero [48]. Therefore, the reaction taking place proceeds without producing any changes in the resistance of the sensor.

\section{Conclusion}

A series of pure and Fe-doped strontium titanate $\left(\mathrm{SrFe}_{\mathrm{x}} \mathrm{Ti}_{1-\mathrm{x}} \mathrm{O}_{3}\right)$ samples were synthesized, characterized and used to fabricate gas sensors. XPS measurements substantiated that Fe-doped samples displayed a characteristic p-type nature that correlates with observed gas sensing response. Different compositions were investigated for ethanol gas between temperature ranges of $350{ }^{\circ} \mathrm{C}-500^{\circ} \mathrm{C}$. This is to our knowledge, the first example of p-type thick film $\left(\mathrm{SrFe}_{\mathrm{x}} \mathrm{Ti}_{1-\mathrm{x}} \mathrm{O}_{3}(\mathrm{x}=0.0,0.1,0.2)\right)$ being used for ethanol sensing at low concentrations $(5-50 \mathrm{ppm})$. Fe-doped $\mathrm{SrTiO}_{3}$ demonstrated noticeable increase in responsiveness to ethanol gas at $400{ }^{\circ} \mathrm{C}\left(\mathrm{R} / \mathrm{R}_{0}=16.91\right.$ at $\left.50 \mathrm{ppm}\right)$ as compared with pure sample. However, at low temperature $\left(350^{\circ} \mathrm{C}\right)$ sensor shows no prominent gas response whereas at high temperature $\left(500{ }^{\circ} \mathrm{C}\right.$ and above) the response starts to decrease. Furthermore, it was also observed that sensor displayed least cross sensitivity when tested against variety of reducing and oxidizing gases. Summarizing, Fe-doped $\mathrm{SrTiO}_{3}$ sensor show marked enhancement in response towards ethanol as compared with pure $\mathrm{SrTiO}_{3}$. Thus, fabricated sensors due to ease of production, low synthesis cost of materials and sensor electronics along with high sensitivity show great potential to be utilized for more effective ethanol detection at low concentration such as breath monitoring and food stuff quality control.

\section{Acknowledgement}

VL, IPP and NS are thankful to UGC-UKIERI Thematic Partnership Grant 2013 award which supported this work. VL and NS are thankful to Star College Grant (Department of Biotechnology) to Gargi College wide SAN/No.102/IFD/DBT/SAN/1911/2008-09. We are also thankful to Principal Gargi College and University Science and Instrumentation Centre (USIC), University of Delhi. The authors are thankful to Mr. Sachin Kumar for providing help in gas test runs.

\section{References}

[1] T. Seiyama, A. Kato, K. Fujiishi, M. Nagatani, A new detector for gaseous components using semiconductive thin films, Anal. Chem. 34 (1962) 1502-1503.

[2] J. Gerblinger, K.H. Härdtl, H. Meixner, R. Aigner, High-temperature microsensors, Sensors A Compr. Surv. 8 (1995) 181. Weinheim.

[3] M.L. Post, J.J. Tunney, D. Yang, X. Du, D.L. Singleton, Material chemistry of 
perovskite compounds as chemical sensors, Sens. Actuators B Chem. 59 (1999) 190-194.

[4] S. Steinsvik, R. Bugge, J. Gjonnes, J. Tafto, T. Norby, The defect structure of $\mathrm{SrTi}_{1-\mathrm{x}} \mathrm{Fe}_{\mathrm{x}} \mathrm{O}_{3-\mathrm{y}}(\mathrm{x}=0-0.8)$ investigated by electrical conductivity measurements and electron energy loss spectroscopy (EELS), J. Phys. Chem. Solids 58 (1997) 969-976.

[5] R. Moos, N. Izu, F. Rettig, S. Reiß, W. Shin, I. Matsubara, Resistive oxygen gas sensors for harsh environments, Sensors 11 (2011) 3439-3465.

[6] S. Molin, W.L. Iwaniak, B. Kusz, M. Gazda, P. Jasinski, Structural and electrica properties of $\mathrm{Sr}(\mathrm{Ti}, \mathrm{Fe}) \mathrm{O}_{3-\delta}$ materials for SOFC cathodes, J. Electroceram. 28 (2012) $80-87$.

[7] O.A. Marina, N.L. Canfield, J.W. Stevenson, Thermal, electrical, and electrocatalytical properties of lanthanum-doped strontium titanate, Solid State Ionics 149 (2002) 21-28.

[8] K. Sahner, R. Moos, M. Matam, J.J. Tunney, M. Post, Hydrocarbon sensing with thick and thin film p-type conducting perovskite materials, Sens. Actuators B Chem. 108 (2005) 102-112.

[9] J. Exner, M. Schubert, D. Hanft, T. Stöcker, P. Fuierer, R. Moos, Tuning of the electrical conductivity of $\mathrm{Sr}(\mathrm{Ti}, \mathrm{Fe}) \mathrm{O}_{3}$ oxygen sensing films by aerosol codeposition with $\mathrm{Al}_{2} \mathrm{O}_{3}$, Sens. Actuators B Chem. 230 (2016) 427-433.

[10] W. Menesklou, H.J. Schreiner, K.H. Härdtl, E.I. Tiffée, High temperature oxygen sensors based on doped $\mathrm{SrTiO}_{3}$, Sens. Actuators B Chem. 59 (1999) 184-189.

[11] M.S. Wrighton, A.B. Ellis, P.T. Wolczanski, D.L. Morse, H.B. Abrahamson, D.S. Ginley, Strontium titanate photoelectrodes, efficient photoassisted electrolysis of water at zero applied potential, J. Am. Chem. Soc. 98 (1976) 2774-2779.

[12] T. Kawada, T. Watanabe, A. Kaimai, K. Kawamura, Y. Nigara, J. Mizusaki, High temperature transport properties in $\mathrm{SrTiO}_{3}$ under an oxygen potential gradient, Solid State Ionics 108 (1998) 391-402.

[13] T.D. McColm, J.T.S. Irvine, B site doped strontium titanate as a potential SOFC substrate, Ionics 7 (2001) 116-121.

[14] A. Šutka, M. Kodu, R. Pärna, R. Saar, I. Juhnevica, R. Jaaniso, V. Kisand, Orthorhombic $\mathrm{CaFe}_{2} \mathrm{O}_{4}$ : a promising p-type gas sensor, Sens. Actuators B Chem. 224 (2016) 260-265.

[15] P. Ivanov, E. Llobet, X. Vilanova, J. Brezmes, J. Hubalek, X. Correig, Development of high sensitivity ethanol gas sensors based on Pt-doped $\mathrm{SnO}_{2}$ surfaces, Sens. Actuators B Chem. 99 (2004) 201-206.

[16] Q. Wan, Q.H. Li, Y.J. Chen, T.H. Wang, X.L. He, J.P. Li, C.L. Lin, Fabrication and ethanol sensing characteristics of ZnO nanowire gas sensors, Appl. Phys. Lett. 84 (2004) 3654-3656.

[17] V. Luthra, A. Singh, D.C. Pugh, I.P. Parkin, Ethanol sensing characteristics of $\mathrm{Zn}_{0.99} \mathrm{M}_{0.01} \mathrm{O}$ (M=Al/Ni) nanopowders, Phys. Status Solidi A 213 (2015) 1-7.

[18] Y. Li, W. Woldarski, K. Galatsis, S.H. Moslih, J. Cole, S. Russo, N. Rockelmann, Gas sensing properties of p-type semiconducting $\mathrm{Cr}$ doped $\mathrm{TiO}_{2}$ thin films, Sens. Actuators B Chem. 83 (2002) 160-163.

[19] D. Niemeyer, D.E. Williams, P. Smith, K.F.E. Pratt, B. Slater, C. Richard, A. Catlow, A.M. Stoneham, Experimental and computational study of the gassensor behavior and surface chemistry of the solid-solution $\mathrm{Cr}_{2-\mathrm{x}} \mathrm{Ti}_{\mathrm{x}} \mathrm{O}_{3}$ $(\mathrm{x} \leq 0.5)$, J. Mater. Chem. 12 (2002) 667-675.

[20] H. Trabelsi, M. Bejar, E. Dhahri, M.P.F. Graca, M.A. Valente, M.J. Soares, N.A. Sobolev, Raman, EPR and ethanol sensing properties of oxygen-Vacancies $\mathrm{SrTiO}_{3-\delta}$ compounds, Appl. Surf. Sci. 426 (2017) 386-390.

[21] S.K. Hodak, T. Supasai, A. Wisitsoraat, J.H. Hodak, Design of low cost gas sensor based on $\mathrm{SrTiO}_{3}$ and $\mathrm{BaTiO}_{3}$ films, J. Nanosci.Nanotechnol. 10 (2010) 7236-7238.

[22] A. Stratulat, B.C. Serban, A. de Luca, V. Avramescu, C. Cobianu, M. Brezeanu, O. Buiu, L. Diamandescu, M. Feder, S.Z. Ali, F. Udrea, Low power resistive oxygen sensor based on sonochemical $\mathrm{SrTi}_{0.6} \mathrm{Fe}_{0.4} \mathrm{O}_{2.8}$ (STFO40), Sensors 15 (2015) 17495-17506

[23] G.F. Fine, L.M. Cavanagh, A. Afonja, R. Binions, Metal oxide semi-conductor gas sensors in environmental monitoring, Sensors 10 (2010) 5469-5502.

[24] M. Mishra, S. Krishna T.C, N. Aggarwal, M. Kaur, S. Singh, G. Gupta, Pit assisted oxygen chemisorption on GaN surfaces, Phys. Chem. Chem. Phys. 17 (2015) 15201-15208.

[25] S.C. Naisbitt, K.F.E. Pratt, D.E. Williams, I.P. Parkin, A microstructural model of semiconducting gas sensor response: the effects of sintering temperature on the response of chromium titanate (CTO) to carbon monoxide, Sens. Actuators B Chem. 114 (2006) 969-977.

[26] S. Fuentes, P. Muñoz, N. Barraza, E. Chávez-Ángel, C.M. Sotomayor Torres, Structural characterisation of slightly Fe-doped $\mathrm{SrTiO}_{3}$ grown via a sol-gel hydrothermal synthesis, J. Sol-Gel Sci. Technol. 75 (2015) 593-601.

[27] N.V. Minh, D.T.T. Phuong, $\mathrm{SrTi}_{1-x} \mathrm{Fe}_{\mathrm{x}} \mathrm{O}_{3}$ nanoparticle: a study of structural, optical, impedance and magnetic properties, J. Exp. Nanosci. 6 (3) (2011) 226-237.

[28] L.F. da Silva, M.I.B. Bernardi, L.J.Q. Maia, G.J.M. Frigo, V.R. Mastelaro, Synthesis and thermal decomposition of $\mathrm{SrTi}_{1-\mathrm{x}} \mathrm{Fe}_{\mathrm{x}} \mathrm{O}_{3}(0.0 \leq \mathrm{x} \leq 0.1)$ powders obtained by the polymeric precursor method, J. Therm. Anal. Calorim. 97 (2009) 173-177.

[29] M. Ghaffari, M. Shannon, H. Hui, O.K. Tan, A. Irannejad, Preparation, surface state and band structure studies of $\operatorname{SrTi}_{(1-x)} \mathrm{Fe}_{(x)} \mathrm{O}_{(3-\delta)}(\mathrm{x}=0-1)$ perovskitetype nano structure by $\mathrm{X}$-ray and ultraviolet photoelectron spectroscopy, Surf. Sci. 606 (2012) 670-677.

[30] L. Chen, J. Hu, S. Fang, Z. Han, M. Zhao, Z. Wu, X. Liu, H. Qin, Ethanol-sensing properties of $\mathrm{SmFe}_{1-\mathrm{X}} \mathrm{Ni}_{\mathrm{X}} \mathrm{O}_{3}$ perovskite oxides, Sens. Actuators B Chem. 139 (2009) 407-410

[31] K. Sahner, R. Moos, M. Matam, M. Post, Thick and thin film p-type conducting perovskite hydrocarbon sensors - a comparative study, Sensors 3 (2003) 926-931.

[32] X. Liu, B. Cheng, J. Hu, H. Qin, M. Jiang, Semiconducting gas sensor for ethanol based on $\mathrm{LaMg}_{\mathrm{x}} \mathrm{Fe}_{1-\mathrm{x}} \mathrm{O}_{3}$ nanocrystals, Sens. Actuators B Chem. 129 (2008) 53-58.

[33] W. Haron, A. Wisitsoraat, S. Wongnawa, Nanocrystalline $\mathrm{LaFeO}_{3}$ perovskite oxide perovskite oxide perovskite oxide prepared at lower temperature with improved ethanol gas sensoring, in: Int'l Conference on Biotechnology, Nanotechnology \& Environmental Engineering (ICBNE'15), 2015, pp. 10-13.

[34] Y. Wang, J. Chen, X. Wu, Preparation and gas-sensing properties of perovskitetype $\mathrm{SrFeO}_{3}$ oxide, Mater. Lett. 49 (2001) 361-364.

[35] M. Zhao, H. Peng, J. Hu, Z. Han, Effect of Cobalt doping on the microstructure, electrical and ethanol-sensing properties of $\mathrm{SmFe}_{1-\mathrm{x}} \mathrm{CO}_{\mathrm{x}} \mathrm{O}_{3}$, Sens. Actuators $\mathrm{B}$ Chem. 129 (2008) 953-957.

[36] J.W. Fergus, Perovskite oxides for semiconductor-based gas sensors, Sens. Actuators B Chem. 123 (2007) 1169-1179.

[37] A. Rothschild, W. Menesklou, H.L. Tuller, E.I. Tiffée, Electronic structure, defect chemistry, and transport properties of $\mathrm{SrTi}_{1-\mathrm{x}} \mathrm{Fe}_{\mathrm{x}} \mathrm{O}_{3-\mathrm{y}}$ solid solutions, Chem. Mater. 18 (2006) 3651-3659.

[38] A. Rothschild, S.J. Litzelman, H.L. Tuller, W. Menesklou, T. Schneider, E.I. Tiffée, Temperature-independent resistive oxygen sensors based on $\mathrm{SrTi}_{1-\mathrm{x}} \mathrm{Fe}_{\mathrm{x}} \mathrm{O}_{3-\mathrm{y}}$ solid solutions, Sens. Actuators, B Chem. 108 (2005) 223-230.

[39] T. Higuchi, T. Tsukamoto, Electronic structure of p-type $\mathrm{SrTiO}_{3}$ by photoemission spectroscopy, Phys. Rev. B 57 (1998) 6978-6983.

[40] J. Robertson, Band offsets of wide-band-gap oxides and implications for future electronic devices, J. Vac. Sci. Technol. B 18 (2000) 1785-1791.

[41] R.P. Vasquez, X-ray photoelectron spectroscopy study of $\mathrm{Sr}$ and Ba compounds, J. Electron. Spectrosc. Relat. Phenom. 56 (1991) 217-240.

[42] V.E. Bochenkov, G.B. Sergeev, Preparation and chemiresistive properties of nanostructured materials, Adv. Colloid Interface Sci. 116 (2005) 245-254.

[43] S.M. Kanan, O.M. El-Kadri, I.A.A. Yousef, M.C. Kanan, Semiconducting meta oxide based sensors for selective gas pollutant detection, Sensors 9 (2009) 8158-8196.

[44] N. Barsan, C. Simion, T. Heine, S. Pokhrel, U. Weimar, Modeling of sensing and transduction for p-type semiconducting metal oxide based gas sensors, J. Electroceram. 25 (2010) 11-19.

[45] D.C. Pugh, V. Luthra, A. Singh, I.P. Parkin, Enhanced gas sensing performance of indium doped zinc oxide nanopowders, RSC Adv. 5 (2015) 85767-85774.

[46] G.P. Evans, D.J. Buckley, N.T. Skipper, I.P. Parkin, Single-walled carbon nanotube composite inks for printed gas sensors: enhanced detection of $\mathrm{NO}_{2}, \mathrm{NH}_{3}$, EtOH and acetone, RSC Adv. 4 (2014) 51395-51403.

[47] H.J. Kim, J.H. Lee, Highly sensitive and selective gas sensors using p-type oxide semiconductors: overview, Sens. Actuators B Chem. 192 (2014) 607-627.

[48] F.H. Garzon, R. Mukundan, E.L. Brosha, Solid-state mixed potential gas sensors: theory, experiments and challenges, Solid State Ionics 136 (2000) 633-638. 